\title{
Comparison of gSSR and EST-SSR markers for analyzing genetic variability among tomato cultivars (Solanum lycopersicum L.)
}

\author{
R. Zhou ${ }^{1,2}$, Z. Wu ${ }^{1,2}$, F.L. Jiang ${ }^{1,2}$ and M. Liang ${ }^{2}$ \\ ${ }^{1}$ Key Laboratory of Horticultural Plant Biology and Germplasm Innovation in East \\ China, Ministry of Agriculture, Nanjing, China \\ ${ }^{2}$ College of Horticulture, Nanjing Agricultural University, Nanjing, China \\ Corresponding author: Z. Wu \\ E-mail:wzh@njau.edu.cn \\ Genet. Mol. Res. 14 (4): 13184-13194 (2015) \\ Received April 10, 2015 \\ Accepted August 19, 2015 \\ Published October 26, 2015 \\ DOI http://dx.doi.org/10.4238/2015.October.26.14
}

\begin{abstract}
In order to study genetic variability and develop better strategies for the utilization of 48 tomato cultivars from America, China, the Netherlands, and Portugal, genomic simple sequence repeat (gSSR) and EST-derived SSR (EST-SSR) markers were applied. In all, 15 of $82 \mathrm{gSSR}$ and 18 of 115 EST-SSR markers showed polymorphic loci. There were 995 and 2072 clear fragments amplified by polymorphic gSSR and EST-SSR markers, respectively. The total and average number of alleles detected by EST-SSRs $(75,4.2)$ was more than gSSRs $(54,3.6)$ as a result of some multi-locus EST-SSRs. A lower polymorphism information content value was found in gSSRs (0.529) compared to EST-SSRs (0.620). Similarity coefficient matrixes of the 48 tomato cultivars were established based on the gSSRs and EST-SSRs, and UPGMA dendrograms were constructed from the gSSRs and EST-SSRs similarity coefficient matrixes. A high similarity was observed between the gSSRs and EST-SSRs dendrograms. Genetic variability of four tomato populations from different countries showed that the observed number of alleles and Nei's genetic diversity were highest in the American population, and the effective number of alleles was
\end{abstract}


highest in the Dutch population. The estimated genetic structure showed some tomato cultivars from different countries shared a common genetic background, which might be related to gene flow. It was inferred that both gSSR and EST-SSR markers were effective to assess genetic variability of tomato cultivars, and the combination of both markers could be more effective for genetic diversity analysis in tomato.

Key words: Tomato cultivars; gSSR; EST-SSR; Dendrogram; Estimated genetic structure; Genetic variability

\section{INTRODUCTION}

The tomato (Solanum lycopersicum L.), originating in the Andes mountains of South America, is one of the most important vegetables in the world and is widely grown both in fields and under protected cultivation. Most of the commercial cultivars of tomato have been developed through traditional breeding and phenotypic selection. The initial narrow genetic bases of tomatoes have been further restricted by the development of cultivars and diversity within cultivated tomatoes has been lost (Williams and Clair, 1993). The range of similarity among improved tomato cultivars is narrow (Terzopoulos and Bebeli, 2008). It is vital to analyze the genetic diversity of tomatoes for their further utilization in breeding programs (Mazzucato et al., 2010). A thorough analysis of the genetic variability and structure of germplasm accessions is a fundamental requirement for the effective use of plant materials for breeding and crop improvement.

Today, molecular markers are recognized as a reliable approach for germplasm identification among plant genotypes. Genetic diversity and variability studies of plants have been carried out using molecular markers such as amplified fragment length polymorphisms (AFLPs) (Park et al., 2004; García-Lampason et al., 2012), randomly amplified polymorphic DNAs (RAPDs) (Hend et al., 2009; Nikoiumanesh et al., 2011), inter-simple sequence repeats (ISSRs) (Christopoulos et al., 2010), and simple sequence repeats or microsatellites (SSRs) (Hormaza, 2002; Benor et al., 2008; Pirseyedi et al., 2010). SSRs have shown higher efficiency among these markers due to the reproducibility, codominance, and polymorphism of SSR markers (Powell et al., 1996). Genomic simple sequence repeats (gSSRs) distributed in exons or untranslated-regions have been applied to genetic identification and polymorphism analysis (Nas et al., 2011; Giovannini et al., 2012). Alternatively, SSRs could be developed from available expressed sequence tags (ESTs), which are specially associated with functional genes, with less cost and time. With the sharp development of ESTs, ESTSSRs have been applied in the genetic diversity analysis of various crops (Jia et al., 2007; Huang et al., 2010; Korir et al., 2014). Both gSSR and EST-SSR markers were effectively used in mapping and identifying quantitative trait loci (QTL) (Sraphet et al., 2011). In cucumber, the combination of gSSRs and EST-SSRs resulted in a more effective genetic diversity analysis (Hu et al., 2011).

Tomato is a cultivated species well suited to the analysis of the effect of breeding in shaping diversity (Sim et al., 2009). In this study, we collected 48 tomato cultivars from America, China, the Netherlands, and Portugal, where they are popular in local marketplaces for their organoleptic qualities. In all, 82 gSSR primers and 115 EST-SSRs were screened and the polymorphic markers were used for further genetic variability analysis. The aim of this study was to compare the gSSR and EST-SSR markers when analyzing genetic variability, and to characterize the genetic variability of the tomato cultivars from different countries. This information will be valuable for optimizing the management of tomato collections and for designing crosses that maximize variability in breeding programs. 


\section{MATERIAL AND METHODS}

\section{Plant material}

The tomato germplasm collection used included 48 tomato cultivars. There were 28 cultivars from America, seven cultivars from Mainland of China, four cultivars from Taiwan of China, seven cultivars from the Netherlands, and two cultivars from Portugal. The abbreviations and cultivar names of the 48 tomato cultivars are shown in Table 1.

\begin{tabular}{|c|c|c|c|}
\hline Abbreviation & Cultivar name & Abbreviation & Cultivar name \\
\hline AM01 & Ace 55 UF & AM25 & Tomato Bush Silvery Fir Tree \\
\hline AM02 & Amama Orange & AM26 & Tomato Cherry Gardener's Delight \\
\hline AM03 & Beef Steak & AM27 & Yellow Pear \\
\hline AM04 & Black Krim & AM28 & Stupice \\
\hline AM05 & Bonnie Best & MA29 & Di huang huang yin tao \\
\hline AM06 & Burpee's BigBoy Hybrid & MA30 & Di huang fen tian shi \\
\hline AM07 & C Gardener's D & MA31 & Ai guan sha \\
\hline AM08 & Cherry Rainbow Blend & MA32 & Chao yan \\
\hline AM09 & Cherry Sugar Sweetie & MA33 & Fu shi No. 3 \\
\hline AM10 & Cherry Sun Gold & MA34 & Fu shi No. 6 \\
\hline AM11 & German Johnson & MA35 & Fu shi qiang \\
\hline AM12 & Lemon Boy & TA36 & V-185 \\
\hline AM13 & Pole Black Krim & TA37 & Gold Small Tomato \\
\hline AM14 & Pole Brandywine & TA38 & Double Color Big Tomato \\
\hline AM15 & Pole Brandywine Red \& Yellow & TA39 & Double Color Small Tomato \\
\hline AM16 & Pole Speckled Roman & NE40 & Improved Cairo \\
\hline AM17 & Prudens Purple & NE41 & Hao na \\
\hline AM18 & Red Cherry & NE42 & Ji na \\
\hline AM19 & Roma & NE43 & Jia li \\
\hline AM20 & San Marzano & NE44 & Cairo \\
\hline AM21 & Super Sweet 100 Hybrid & NE45 & Luo man na \\
\hline AM22 & Tomato Cherry Supersweet & NE46 & Sabata \\
\hline AM23 & Tomato Grape Telly Bean Red \& Yellow & $\mathrm{PO} 47$ & Portuguese Tomato \\
\hline AM24 & Tomato Pole Beefsteak & PO48 & Ref Vermelho \\
\hline
\end{tabular}

The first two letters of the abbreviations referred to the origin of the cultivar (AM, America; MA, Mainland of China; TA, Taiwan of China; NE, Netherlands; PO, Portugal), followed by two serial numbers.

\section{DNA isolation}

Total genomic DNA was isolated from young leaves of 50-day-old seedlings using a DNA extraction kit (Takara, Shanghai, China) following the manufacturer instructions. A 1\% agarose gel electrophoresis was used to assess quality and quantity against known concentrations of unrestricted lambda DNA.

\section{DNA fingerprinting}

The gSSR and EST-SSR markers were commercially synthesized by Invitrogen (Shanghai, China). A total volume of $20 \mu \mathrm{L}$ was used for amplification reactions, containing $11.6 \mu \mathrm{L} \mathrm{ddH_{2 }} \mathrm{O}, 1$ $\mu \mathrm{L}$ gDNA (20 ng), $1 \mu \mathrm{L}$ forward and reverse primer $(10 \mu \mathrm{M}), 2 \mu \mathrm{L}$ 10X Buffer $\mathrm{Mg}(-), 1.2 \mu \mathrm{L} \mathrm{MgCl}{ }_{2}$ (25 mM), $2 \mu \mathrm{L}$ dNTPs $(2.5 \mathrm{mM})$, and $0.2 \mu \mathrm{L}$ Taq DNA polymerase $(5 \mathrm{U} / \mu \mathrm{L})$ (Takara, Shanghai, China). The amplification reactions were carried out in 96-well plates in an Authorized Thermal Cycler (Eppendorf, Hamburg, Germany) with the following program: $94^{\circ} \mathrm{C}$ for $3 \mathrm{~min}$; then 35 cycles 
of $94^{\circ} \mathrm{C}$ for $45 \mathrm{~s}, 54^{\circ} \mathrm{C}$ for $45 \mathrm{~s}$, and $72^{\circ} \mathrm{C}$ for $1 \mathrm{~min}$; finally $72^{\circ} \mathrm{C}$ for $5 \mathrm{~min}$. The PCR products were verified by $8 \%$ polyacrylamide gel electrophoresis and visualized by silver staining. In order to estimate band sizes, a DL 500 bp DNA marker (Takara, Shanghai, China) was included in each gel. Electrophoresis was run at $100 \mathrm{~V}$ for approximately two hours.

\section{Data analysis}

gSSR and EST-SSR markers showing no bands or consistent bands among the tomato cultivars were eliminated. For the polymorphic markers, the presence or absence of a band was scored as 1 or 0 , respectively. The polymorphism information content (PIC) for the gSSR and ESTSSR markers was calculated using PIC-CALC software according to the formula:

$$
\mathrm{PIC}=1-\sum \mathrm{p}_{\mathrm{ij}}^{2}
$$

where $p_{i j}$ is the frequency of the $i^{\text {th }}$ allele of the $j^{\text {th }}$ marker (Weir, 1990).

As described by Nei and $\mathrm{Li}(1979)$, pairwise genetic similarities $\left(\mathrm{S}_{\mathrm{ij}}\right)$ among accessions i and $\mathrm{j}$ were estimated as follows:

$$
\mathrm{S}_{\mathrm{ij}}=2 \mathrm{~N}_{\mathrm{ij}} /\left(\mathrm{N}_{\mathrm{i}}+\mathrm{N}_{\mathrm{j}}\right)
$$

where $N_{i j}$ is the number of bands present in the $i^{\text {th }}$ and $j^{\text {th }}$ cultivars, with $N_{i}$ and $N_{j}$ representing the number of bands present in cultivar $\mathrm{i}$ and cultivar $\mathrm{j}$, respectively. Based on genetic similarity matrices, a dendrogram was constructed using NTSYSpc version 2.10 software by the unweighted pair group mean analysis method.

The number of polymorphic loci (NPL), observed number of alleles (Na), effective number of alleles (Ne), and Nei's genetic diversity (Nei) were calculated using POPGENE 1.32 (Nei, 1972). Gene flow $(\mathrm{Nm})$ was calculated according to the following formula:

$$
\mathrm{Nm}=0,25 \times(1-\mathrm{Fst}) / \text { Fst }
$$

(Equation 3)

The estimated genetic structure was constructed using the STRUCTURE program of Evanno et al. (2005).

\section{RESULTS}

\section{PCR amplification and allelic variation}

Of the $82 \mathrm{gSSR}$ and $115 \mathrm{EST}-\mathrm{SSR}$ markers, $15 \mathrm{gSSR}$ and 18 EST-SSR markers showed clear polymorphic loci (Table 2). The $67 \mathrm{gSSR}$ and 97 EST-SSR markers showed a consistent strip or no clear strip among the 48 tomato cultivars. There were $18.3 \%$ gSSR and $15.7 \%$ ESTSSR markers with polymorphisms (Table 2). There were 995 clear fragments amplified by 15 polymorphic gSSR markers with an average of 66 fragments per primer in all tomato cultivars (Table 2). The number of alleles ranged from 2 to 5 with a total of 54 alleles and an average of 
3.6 alleles for gSSR markers (Table 2). On the other hand, 2072 fragments were amplified by 18 polymorphic EST-SSR markers with an average of 115 fragments per primer in all tomato cultivars (Table 2). The number of alleles ranged from 3 to 6 with a total of 75 alleles and an average of 4.2 alleles for EST-SSR markers (Table 2). The average PIC value of the $15 \mathrm{gSSR}$ markers was 0.529 , ranging from 0.291 to 0.698 (Table 2). The average PIC value of 18 EST-SSR markers was 0.620 with a range of 0.391 to 0.800 (Table 2 ).

The sequence, annealing temperature, allele number, and expected size of the polymorphic gSSR and EST-SSR markers were shown in Table 3. The DNA fingerprints of the 48 tomato cultivars as given by EST-SSR7 are shown in Figure 1.

Table 2. Summary of microsatellite allele data revealed by polymorphic microsatellite loci in the 48 tomato cultivars.

\begin{tabular}{lrr}
\hline Item & gSSR & EST-SSR \\
\hline Percentage of polymorphic primers (\%) & 18.3 & 15.7 \\
Number of polymorphic primers & 15 & 18 \\
Number of all fragments & 995 & 2072 \\
Average number of fragments per primer pair & 66 & 115 \\
Number of all alleles & 54 & 75 \\
Average number of alleles per primer pair & 3.6 & 4.2 \\
Polymorphism information content (range/mean) & $0.291-0.698 / 0.529$ & $0.391-0.800 / 0.620$ \\
\hline
\end{tabular}

Table 3. Polymorphic gSSR and EST-SSR primer pairs used for further analysis in this study.

\begin{tabular}{|c|c|c|c|c|c|}
\hline Marker name & Forward primer ( $5^{\prime}$ to $\left.3^{\prime}\right)$ & Reverse primer ( $5^{\prime}$ to $\left.3^{\prime}\right)$ & $\begin{array}{c}\text { Annealing } \\
\text { temperature }\left({ }^{\circ} \mathrm{C}\right)\end{array}$ & Allele & $\begin{array}{l}\text { Expected } \\
\text { size (bp) }\end{array}$ \\
\hline \multicolumn{6}{|l|}{ gSSR } \\
\hline Al895937 & CATAATCACAAGCTTCTTTCGCCA & CATATCCGCTCGTTTCGTTATGTAAT & 54 & 3 & $150-200$ \\
\hline X13437 & GAGCACCCATTAATTTCGTTACG & GTGGCGGATCTAGAAATTTAAACTG & 55 & 3 & $200-300$ \\
\hline SSR111 & GTCCAGTGTTTCCAAAGGGA & TTTGCTGCTATACTGCTGACA & 50 & 4 & $150-300$ \\
\hline Tom 31-32 & AATGTCCTTCGTATCCTTTCGT & CTCGGTTTTAATTTTTGTGTCT & 52 & 5 & $100-250$ \\
\hline Al780156 & TCCAATTTCAGTAAGGACCCCTC & CCGAAAACCTTTGCTACAGAGTAGA & 56 & 3 & $100-250$ \\
\hline AW037347 & GCCACGTAGTCATGATATACATAG & GCCTCGGACAATGAATTG & 54 & 2 & $100-250$ \\
\hline LE21085 & CATTTTATCATTTATTTGTGTCTTG & ACAAAAAAAGGTGACGATACA & 54 & 4 & $100-250$ \\
\hline SSR47 & TCCTCAAGAAATGAAGCTCTGA & CCTTGGAGATAACAACCACAA & 52 & 4 & $150-300$ \\
\hline TOM236-237 & GTTTTTTCAACATCAAAGAGCT & GGATAGGTTTCGTTAGTGAACT & 54 & 4 & $100-200$ \\
\hline Al491173 & GCACGAGCACATATAGAAGAGAATCA & ССАTTTCATCATATCTCTCAGCTTGC & 52 & 3 & $150-200$ \\
\hline Al897173 & ССТСТСТТСАССТСТТТАСААТТTСС & CACTGGTCATTAAGTCTACAGCC & 54 & 2 & $50-150$ \\
\hline TMS6 & СTCTCTCAATGTTTGTCTTTC & GCAAGGTAGGTAGCTAGGGA & 54 & 3 & $150-300$ \\
\hline U2108 & CATTTTATCATTTATTTGTGTCTTG & ACAAAAAAAGGTGACGATACA & 53 & 4 & $100-200$ \\
\hline LEMDDNa & ATTCAAGGAACTTTTTAGCTCC & TGCATTAAGGTTCATAAATGA & 54 & 4 & $200-250$ \\
\hline LE20592 & CTGTTTACTTCAAGAAGGCTG & ACTTTAACTTTATTATTGCCACG & 53 & 5 & $150-300$ \\
\hline \multicolumn{6}{|l|}{ EST-SSR } \\
\hline EST-SSR1 & АССTACCTGTCTCCGССTCT & TGACAAGGTAAAGCCAACCC & 55 & 5 & $150-300$ \\
\hline EST-SSR2 & CTTATGTGAAAACACCTCGCTC & TTCAAAATTCCCCAAAGACG & 54 & 4 & $50-150$ \\
\hline EST-SSR7 & GAAGAAGATGGTGGGGATGA & CTTGCAACAATCGTGAATGC & 54 & 4 & $50-150$ \\
\hline EST-SSR19 & АCСТGCACACACCACACACT & GATCAAAGAAGCGGGATGAT & 53 & 4 & $100-150$ \\
\hline EST-SSR23 & TAGACTGGGCCTGTGGTCTT & TGGTGAATCAATTTTGGGGT & 52 & 3 & $100-150$ \\
\hline EST-SSR25 & ATTGGGGAATGGGTTTTCTC & AAACGAAGGCAACAACGAAG & 54 & 4 & $100-200$ \\
\hline EST-SSR26 & TCAAATGGCTTCTCTTGTTCTTT & TTGTTGGAAACTCCTTTGGC & 54 & 3 & $100-150$ \\
\hline EST-SSR35 & CATAAGAAGAAAGGTGTGAATGAGA & GTTGCTTTGTCTTTGTCGCC & 52 & 6 & $100-200$ \\
\hline EST-SSR42 & CCAAAAGAAGTGGGTCCAAA & AAACTAGCGACAAATAAAAGCAGA & 54 & 6 & $100-200$ \\
\hline EST-SSR62 & AATACCCGAAAATGACCGAA & TGGCTGGTGATACCACCTCT & 54 & 3 & $100-200$ \\
\hline EST-SSR71 & GGACCAAGCGAAGTTGGATA & CGAGTGTTTCGCTTCTCCTC & 54 & 3 & $100-200$ \\
\hline EST-SSR74 & GGATTTCGTCGATTTCCATAA & GАTTCСТTCCAАTACACAАTTCAA & 50 & 5 & $150-200$ \\
\hline EST-SSR77 & GAGGACGACAACAACAACGA & GACATGCCACTTAGATCCACAA & 53 & 5 & $100-200$ \\
\hline EST-SSR80 & GGTTTAATATCATTCACATATGCTCG & GATCAGGGCCAAGAATTGAA & 52 & 5 & $150-300$ \\
\hline EST-SSR83 & TTAGGCAGCTTACGACTGGA & ССАСАAАТTСТTТTССССАА & 51 & 3 & $150-200$ \\
\hline EST-SSR85 & GCCCATATTAAGCCCAAAAA & AGACAGCATGAGGTCCGAAT & 51 & 3 & $150-200$ \\
\hline EST-SSR97 & CTCGAACCCTGTACCACACC & TGCTGTCGCTTTCATTATCG & 54 & 6 & $150-300$ \\
\hline EST-SSR106 & TGTCAATCCACCTGGCATAA & AGGAGGTGCGTAAGGAGGAT & 54 & 3 & $50-150$ \\
\hline
\end{tabular}




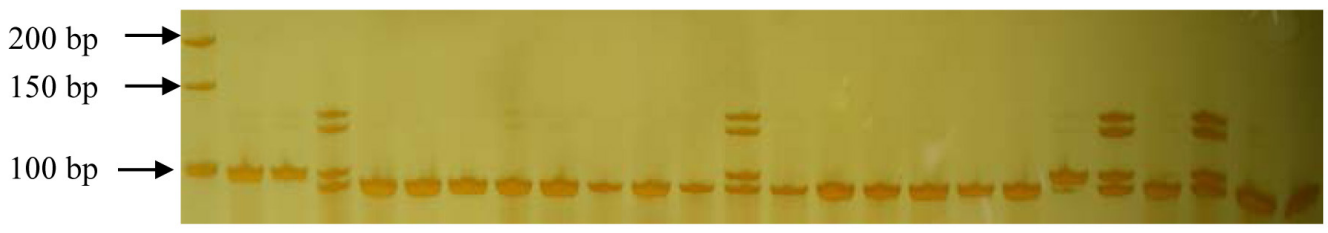

M 010203040506070809101112131415161718192021222324

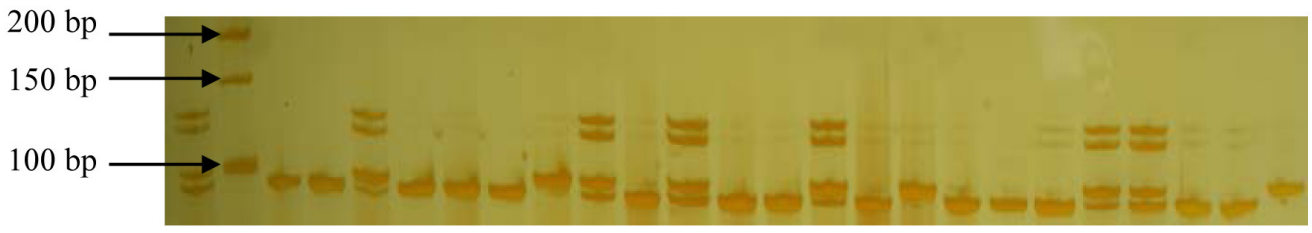

25 M 2627282930313233343536373839404142434445464748

Figure 1. Profile amplified by EST-SSR7 in the 48 tomato cultivars. Lane M: DL 500 bp DNA marker; Lanes 01-48: cultivars AM1-PO48.

\section{Dendrogram of tomato cultivars from gSSR and EST-SSR markers}

The similarity coefficients detected by gSSRs ranged from 0.296 (AM21 and NE44) to 0.944 (AM09 and AM14), with an average of 0.637 (Table S1). And for EST-SSRs, the similarity coefficients ranged from 0.360 (AM13 and AM25) to 0.960 (AM23 and AM24), with an average of 0.671 (Table S2). Two dendrograms were constructed based on the similarity coefficients (Figure 2, 3).

The 48 tomato cultivars were classified into four major clusters with two cultivars (PO48 and AM10) considered as two individual clusters in the gSSRs dendrogram (Figure 2). Cluster I included nine American cultivars. Cluster II comprised 11 American cultivars, seven Chinese cultivars, five Dutch cultivars, and one Portuguese cultivar. Five American cultivars gathered together in cluster III. Eight cultivars from different regions formed Cluster IV.

The 48 tomato cultivars were divided into four clusters in the EST-SSRs dendrogram (Figure 3). There were 27 tomato cultivars from different regions in Cluster I. Cluster II included five American cultivars. Cluster III contained seven American cultivars, two Dutch cultivars, and three Chinese cultivars. Two American, one Chinese, and one Portuguese cultivar were grouped in Cluster IV.

\section{Genetic diversity of four populations from different countries}

The 48 tomato cultivars were classified into four populations by their geographical origins. Analysis of the genetic diversity among the American, Chinese, Dutch, and Portuguese populations are shown in Table 4. The mean number of polymorphic loci (NPL) was 13.75 for the four populations. The highest observed number of alleles $\left(N_{\mathrm{A}}\right)$ was found in the American population (3.467), while the highest effective number of alleles $\left(N_{E}\right)$ was found in the Dutch population (2.579). The highest Nei's genetic diversity (Nei) was observed in the American population (0.5599). The estimated genetic structure was sensitive to the number of loci and the population sample size. The model with $K=5$ gave the most favorable result in this study. The proportion of the five bases in each cultivar is shown in Table S3. The estimated genetic structure derived from the proportion of the five bases showing the genetic background of the 48 tomato cultivars is represented by bars of different colors (Figure 4). 


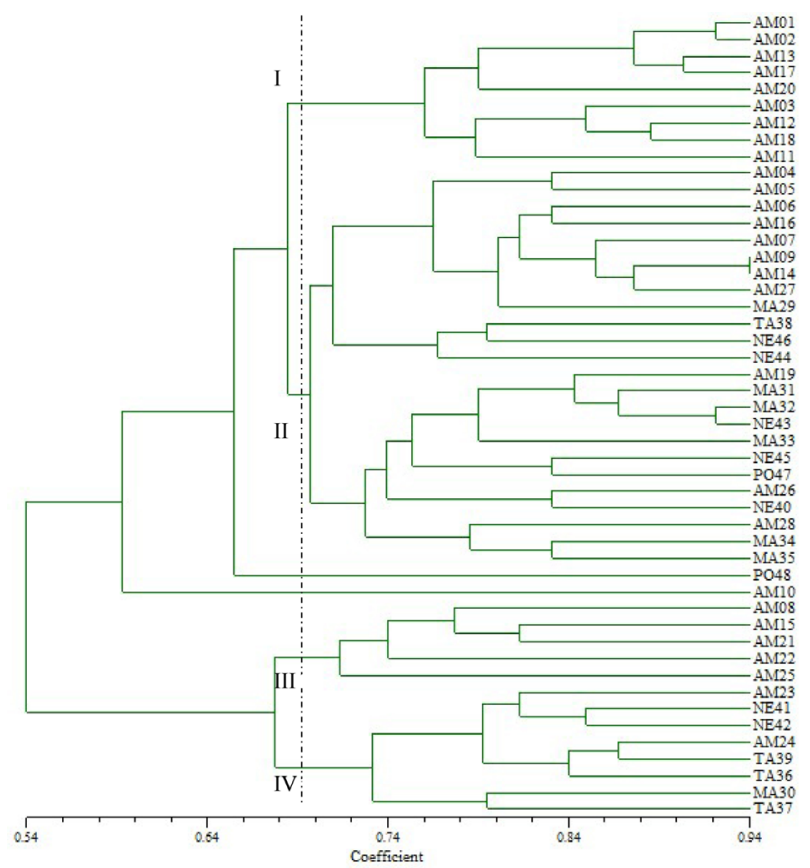

Figure 2. UPGMA dendrogram of 48 tomato cultivars using gSSR markers. The codes on the right refer to the abbreviations of the tomato cultivars in Table 1.

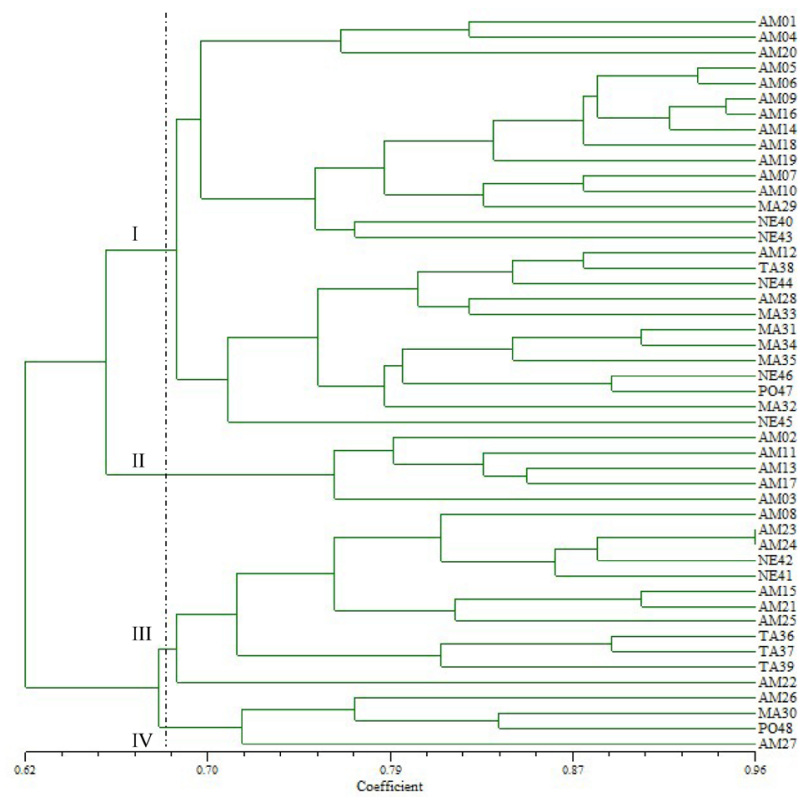

Figure 3. UPGMA dendrogram of 48 tomato cultivars using EST-SSR markers. The codes on the right refer to the abbreviations of the tomato cultivars in Table 1. 


\begin{tabular}{|c|c|c|c|c|c|}
\hline Population & $\mathrm{NPL}^{\mathrm{a}}$ & $\mathrm{Na}^{\mathrm{b}}$ & $\mathrm{Ne}^{\mathrm{c}}$ & $\mathrm{Nei}^{\mathrm{d}}$ & $\mathrm{Nm}^{\mathrm{e}}$ \\
\hline America & 15 & 3.467 & 2.559 & 0.560 & - \\
\hline China & 15 & 3.267 & 2.392 & 0.519 & - \\
\hline Netherlands & 15 & 3.200 & 2.579 & 0.544 & - \\
\hline Portugal & 10 & 2.000 & 1.892 & 0.404 & - \\
\hline Mean & 13.75 & 2.983 & 2.355 & 0.507 & - \\
\hline Overall & - & 3.600 & 2.579 & 0.566 & 1.547 \\
\hline
\end{tabular}

${ }^{\mathrm{a}}$ number of polymorphic loci, ${ }^{\mathrm{b}}$ observed number of alleles, ${ }^{\mathrm{C}}$ effective number of alleles, ${ }^{\mathrm{d}}$ Nei's genetic diversity, ${ }^{\mathrm{e}} \mathrm{gene}$ flow.

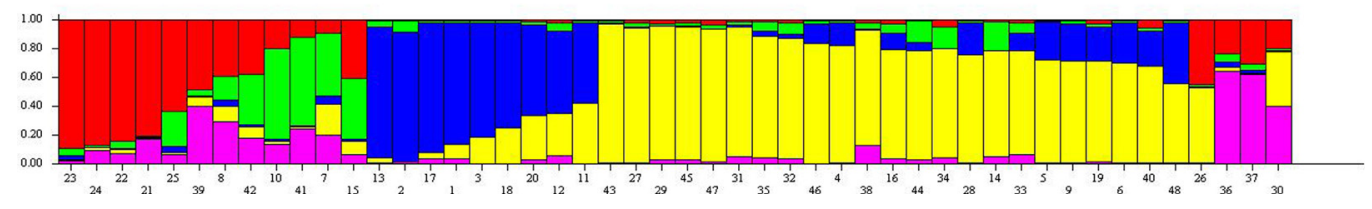

Figure 4. Estimated genetic structure for $K=5$ for tomato genotypes based on gSSR variation. Each vertical bar represents one cultivar listed in Table 1 and the different colors represent different genetic backgrounds.

\section{DISCUSSION}

\section{gSSR and EST-SSR marker selection}

There has been much attention paid to the development and evaluation of SSR markers in tomato. Ohyama et al. (2009) developed nearly 700 SSR markers based on genome databases. Shirasawa et al. (2010) developed EST-derived SSR markers (TES markers), genome-derived SSR markers (TGS markers), and EST-derived intronic polymorphism markers (TEI markers) in tomato. Among the SSR markers, EST-SSR markers have been developed for a wide range of plant species and used for genetic studies with multiple purposes (Caruso et al., 2008; Tehrani et al., 2009; Sraphet et al., 2011; Korir et al., 2014). In this study, 15 out of 82 gSSR primers (18.3\%) and 18 of 115 EST-SSR primers (15.7\%) were polymorphic, indicating that the polymorphism rate of gSSR is higher than that of EST-SSR. A low polymorphism rate in gSSR and EST-SSR among tomato cultivars is probably due to the autogamous nature of tomato. Some markers detected more than two clear and stable bands in some cultivars in our study, and these were considered as multi-locus markers. The total and average number of alleles detected by EST-SSR $(75,4.2)$ is slightly higher than for gSSR $(54,3.6)$. In cucumber, gSSR markers detected more alleles than EST-SSR (Hu et al., 2011). Most of EST-SSRs are multi-locus markers in our study, which might explain why more alleles were detected by EST-SSR than by gSSR.

Polymorphic information content (PIC) was used to measure genetic diversity. Values of $\mathrm{PIC}>0.5,0.5>\mathrm{PIC}>0.25$, and $\mathrm{PIC}<0.25$ were designated as high, medium, and low locus polymorphism, respectively (Xie et al., 2010). The mean values of PIC obtained by gSSR and ESTSSR markers in this study were 0.529 and 0.620 , respectively, demonstrating that both gSSRs and EST-SSRs could develop high locus polymorphism. The PIC of SSRs in cultivated and wild tomatoes was 0.687 (Meng et al., 2010) and the PIC of SSRs in tomato varieties was 0.628 (Kwon et al., 2009), which was similar to the results of this study. The PIC of SSRs in Pomegranate was 0.43 (Pirseyedi et al., 2010), relatively lower than the results of this study. The difference in the PIC of SSRs might be due to the different plant materials. 


\section{Cluster analysis and genetic relationships among tomato cultivars}

Two dendrograms were constructed based on the similarity coefficients derived from the gSSR and EST-SSR markers. There was a clear consistency between gSSR and EST-SSR dendrograms in terms of the positioning of some tomato cultivars. Certain tomato cultivars had close relationships in both dendrograms, such as AM05 and AM06, AM13 and AM17, AM21 and AM25, NE41 and NE42, TA36 and TA39, and MA34 and MA35. The results demonstrated that certain tomato cultivars from the same geographical region had high similarity coefficients. The climate and market orientation in one geographical region might produce a specific breeding approach, which could be the reason for the high similarity coefficients between the tomato cultivars from the same country. However, tomato cultivars did not always cluster according to their geographical origins. For example, PO47 and NE45, and TA38 and NE44 were both close. This suggests that tomato varieties with different geographical origins probably have at least some common genetic bases as a consequence of gene flow.

The 48 tomato cultivars were divided into four populations according to their origins. The highest $\mathrm{Ne}$ was detected in the Dutch population, while the highest $\mathrm{Na}$ and Nei were detected in the American population. The $\mathrm{Nm}$ among the 48 tomato cultivars was 1.547 , which was similar to the $\mathrm{Nm}$ in 75 pomegranate genotypes (1.451) (Parvaresh et al., 2012). The estimated genetic structure indicated that the tomato cultivars from different origins, such as MA29 and NE45, could have similar genetic backgrounds, possibly as a result of gene flow. The results of our study showed that gSSR and EST-SSR markers could be successfully used in the characterization of tomato cultivars and the analysis of genetic diversity, which was also discovered in studies of Panicum virgatum (Narasimhamoorthy et al., 2008) and Prunus divaricata (Wohrmann et al., 2011).

The intensive breeding of crops over the past half century with a focus on yield and special phenotypes has indirectly led to the loss of diversity. Modern tomatoes have been produced by the selective breeding process, leading to an inevitable reduction in their genetic variation (Yi et al., 2008). Estimation of genetic diversity in plant species with a narrow genetic base could be more efficient if different marker systems were used (Hu et al., 2011). gSSRs and EST-SSRs, two kinds of molecular markers, should yield similar cluster results and more reliable conclusions in the assessment of tomato genetic variability.

We compared the gSSR and EST-SSR markers in a genetic variability analysis of tomato cultivars from different countries. EST-SSRs detected more alleles and higher polymorphism information content than gSSRs among the 48 tomato cultivars as a result of multi-locus ESTSSRs. Both gSSR and EST-SSR markers could be efficiently applied in determining the genetic variability of cultivated tomato. A high similarity was observed in dendrograms based on the two markers. Our results are of importance not only for germplasm management, but also for parent selection and cross breeding of these modern tomato cultivars.

\section{Conflicts of interest}

The authors declare no conflict of interest.

\section{ACKNOWLEDGMENTS}

Research supported by the Priority Academic Program Development of Jiangsu Higher Education Institutions (PAPD), the National Undergraduate Innovational Experimentation Program 
(\#NUIEP, 111030723), and the Research Innovation Program for College Graduates of Jiangsu Province (\#CXZZ12-0285).

\section{Supplementary material}

\section{REFERENCES}

Benor S, Zhang MY, Wang ZF and Zhang HS (2008). Assessment of genetic variation in tomato (Solanum lycopersicum L.) inbred lines using SSR molecular markers. J. Genet. Genomics 35: 373-379.

Caruso M, Federici CT and Roose ML (2008). EST-SSR markers for asparagus genetic diversity evaluation and cultivar identification. Mol. Breeding 21: 195-204.

Christopoulos MV, Rouskas D, Tsantili E and Bebeli PJ (2010). Germplasm diversity and genetic relationships among walnut (Juglans regia L.) cultivars and Greek local selections revealed by inter-simple sequence repeat (ISSR) markers. Sci. Hortic. 125: 584-592.

Evanno G, Regnaut S and Goudet J (2005). Detecting the number of clusters of individuals using the software STRUCTURE: a simulation study. Mol. Ecol. 14: 2611-2620.

García-Lampason S, Asprelli P and Burba JL (2012). Genetic analysis of a garlic (Allium sativum L.) germplasm collection from Argentina. Sci. Hortic. 138: 183-189.

Giovannini D, Dettori MT, Leone A, Liverani A, et al. (2012). Assessment of genetic variability in Italian heritage peach resources from Emilia-Romagna using microsatellite markers. J. Hortic. Sci. Biotech. 87: 435-440.

Hend BT, Ghada B, Sana BM, Mohamed M, et al. (2009). Genetic relatedness among Tunisian plum cultivars by random amplified polymorphic DNA analysis and evaluation of phenotypic characters. Sci. Hortic. 121: 440-446.

Hormaza Jl (2002). Molecular characterization and similarity relationships among apricot (Prunus armeniaca L.) genotypes using simple sequence repeats. Theor. Appl. Genet. 104: 321-328.

$\mathrm{Hu}$ J, Wang L and Li J (2011). Comparison of genomic SSR and EST-SSR markers for estimating genetic diversity in cucumber. Biol. Plantarum 55: 577-580.

Huang Y, Li F and Chen KS (2010). Analysis of diversity and relationships among Chinese orchid cultivars using EST-SSR markers. Biochem. Syst. Ecol. 38: 93-102.

Jia XP, Shi YS, Song YC, Wang GY, et al. (2007). Development of EST-SSR in foxtail millet (Setaria italica). Genet. Resour. Crop Evol. 54: 233-236.

Korir NK, Diao W, Tao R, Li X, et al. (2014). Genetic diversity and relationships among different tomato varieties revealed by EST-SSR markers. Genet. Mol. Res. 13: 43-53.

Kwon YS, Park SG and Yi SI (2009). Assessment of genetic variation among commercial tomato (Solanum lycopersicum L.) varieties using SSR markers and morphological characteristics. Genes Genom. 31: 1-10.

Mazzucato A, Ficcadenti N, Caioni M, Mosconi P, et al. (2010). Genetic diversity and distinctiveness in tomato (Solanum lycopersicum L.) landraces: the Italian case study of 'A pera Abruzzese'. Sci. Hortic. 125: 55-62.

Meng FJ, Xu XY, Huang FL and Li JF (2010). Analysis of genetic diversity in cultivated and wild tomato varieties in Chinese market by RAPD and SSR. Agr. Sci. China 9: 1430-1437.

Narasimhamoorthy B, Saha MC, Swaller T and Bouton JH (2008). Genetic diversity in switchgrass collections assessed by EST-SSR markers. Bioenerg. Res. 1: 136-146.

Nas MN, Bolek Y and Bardak A (2011). Genetic diversity and phylogenetic relationships of Prunus microcarpa C.A. Mey. subsp. tortusa analyzed by simple sequence repeats (SSRs). Sci. Hortic. 127: 220-227.

Nei M (1972). Genetic distance between populations. Am. Nat. 106: 283-291.

Nei M and Li WH (1979). Mathematical model for studying genetic variation in terms of restriction endonucleases. Proc. Natl. Acad. Sci. U.S.A. 76: 5269-5273.

Nikoiumanesh K, Ebadi A, Zeinalabedini M and Gogorcena Y (2011). Morphological and molecular variability in some Iranian almond genotypes and related Prunus species and their potentials for rootstock breeding. Sci. Hortic. 129: 108-118.

Ohyama A, Asamizu E, Negoro S, Miyatake K, et al. (2009). Characterization of tomato SSR markers developed using BACend and cDNA sequences from genome databases. Mol. Breeding 23: 685-691.

Park YH, West MAL and Clair DAS (2004). Evaluation of AFLPs for germplasm fingerprinting and assessment of genetic diversity in cultivars of tomato (Lycopersicon esculentum L.). Genome 47: 510-518.

Parvaresh M, Talebi M and Sayed-Tabatabaei BE (2012). Molecular diversity and genetic relationship of pomegranate (Punica granatum L.) genotypes using microsatellite markers. Sci. Hortic. 138: 244-252.

Pirseyedi SM, Valizadehghan S, Mardi M, Ghaffari MR, et al. (2010). Isolation and characterization of novel microsatellite 
markers in pomegranate (Punica granatum L.). Int. J. Mol. Sci. 11: 2010-2016.

Powell W, Morgante M, Andre C, Hanafey M, et al. (1996). The comparison of RFLP, RAPD, AFLP and SSR (microsatellite) markers for germplasm analysis. Mol. Breeding 2: 225-238.

Shirasawa K, Asamizu E, Fukuoka H, Ohyama A, et al. (2010). An interspecific linkage map of SSR and intronic polymorphism markers in tomato. Theor. Appl. Genet. 121: 731-739.

Sim SC, Robbins MD, Chilcott C, Zhu T, et al. (2009). Oligonucleotide array discovery of polymorphisms in cultivated tomato (Solanum lycopersicum L.) reveals patterns of SNP variation associated with breeding. BMC Genomics 10: 466-475.

Sraphet S, Boonchanawiwat A, Thanyasiriwat T, Boonseng O, et al. (2011). SSR and EST-SSR-based genetic linkage map of cassava (Manihot esculenta Crantz). Theor. Appl. Genet. 122: 1161-1170.

Tehrani MS, Mardi M, Sahebi J, Catalán P, et al. (2009). Genetic diversity and structure among Iranian tall fescue populations based on genomic-SSR and EST-SSR marker analysis. Plant Syst. Evol. 282: 57-70.

Terzopoulos PJ and Bebeli PJ (2008). DNA and morphological diversity of selected Greek tomato (Solanum lycopersicum L.) landraces. Sci. Hortic. 116: 354-361.

Weir BS (1990). Genetic data analysis: methods for discrete population genetics data. Sinauer Associates, Inc. Sunderland, MA, USA.

Williams CE and Clair DAS (1993). Phenetic relationships and levels of variability detected by restriction fragment length polymorphism and random amplified polymorphic DNA analysis of cultivated and wild accessions of Lycopersicon esculentum. Genome 36: 619-630.

Wohrmann T, Guicking D, Khoshbakht K and Weising K (2011). Genetic variability in wild populations of Prunus divaricata Ledeb. in northern Iran evaluated by EST-SSR and genomic SSR marker analysis. Genet. Resour. Crop Evol. 58: 1157-1167.

Xie WG, Zhang XQ, Cai HW, Liu W, et al. (2010). Genetic diversity analysis and transferability of cereal EST-SSR markers to orchard grass (Dactylis glomerata L.). Biochem. Syst. Ecol. 38: 740-749.

Yi SS, Jatoi SA, Fujimura T, Yamanaka S, et al. (2008). Potential loss of unique genetic diversity in tomato landraces by genetic colonization of modern cultivars at a non-center of origin. Plant Breed. 127: 189-196. 